\title{
Traços do ragtime no choro Segura ele de Pixinguinha: composição, performance e iconografia após a viagem a Paris em 1922
}

\author{
Nilton Antônio Moreira Júnior (UNIRIO, Rio de Janeiro, RJ) \\ niltonjun@yahoo.com.br
}

Fausto Borém (UFMG, Belo Horizonte. MG)

fborem@ufmg.br

Resumo: Estudo analítico e comparativo sobre os choros Segura ele e Um a zero de Pixinguinha que, na histórica viagem do grupo de choro Oito Batutas a Paris em 1922, conviveu com músicos de jazz norte-americanos. Observam-se características do ragtime em Segura ele a partir das gravações no CD Pixinguinha 100 anos, o qual inclui performances do compositor no saxofone e na flauta. Uma comparação entre elementos formais, harmônicos, rítmicos, motívicos, de instrumentação e iconográficos mostra que o choro de Pixinguinha foi influenciado em vários níveis pelo gênero popular norte-americano.

Palavras-chave: Pixinguinha; choro; ragtime; música popular brasileira; análise musical.

Ragtime traces in the choro Segura ele [Hold him!] by Pixinguinha: composition, performance and iconography after the trip to Paris in 1922

\begin{abstract}
Analytical and comparative study about Segura ele and Um a zero, two choros by Brazilian composer and instrumentalist Pixinguinha, who embarked to Paris in 1922, on the historical trip with his choro group Oito Batutas (Eight Smarties), where he met American jazz musicians. It shows traits of ragtime in Segura ele departing from the recordings of the works in the CD Pixinguinha 100 anos, which includes performances by the composer on both the saxophone and flute. A comparison among formal, harmonic, rhythmic, motivic, instrumentation and iconographic elements reveal that Pixinguinha's choro style was influenced by the US popular music genre in several levels.
\end{abstract}

Keywords: Pixinguinha; choro; ragtime; Brazilian popular music; musical analysis.

\author{
"O artista é o melhor dos veículos \\ para a aproximação dos povos" \\ (Oscar Guanabarino, citado por MARIZ, 1989, p.62)
}

\section{1 - Introdução}

Alfredo da Rocha Vianna, mais conhecido como Pixinguinha (1897-1973), deixou um grande número de composições, especialmente choros, que se tornaram referenciais na música brasileira. A versatilidade da atuação de Pixinguinha nesse gênero - no qual foi compositor, flautista, saxofonista, arranjador e regente - aliada à sua criatividade e curiosidade, o permitiu criar uma linguagem pioneira para suas demandas musicais, e que se tornou modelo para todas as gerações de chorões que se seguiram (CABRAL, 1997, p.13). Uma comparação entre Um a zero e Segura ele, dois choros de sua autoria, mostra que, apesar dessas músicas compartilharem elementos comuns do gênero, a segunda revela traços do gênero norte-americano ragtime.

Uma das ferramentas mais eficientes da nova musicologia para se perceber o cerne da realização musical é a análise de gravações, a exemplo do que tem sido desenvolvido no CHARM (Centre for the HIstory and Analysis of Recorded Music) na Inglaterra, sendo uma de suas vertentes a transcrição musical baseada na audição atenta de gravações. A transcrição e análise de linhas solísticas 
e de acompanhamento, harmonias, ritmos, dinâmicas, articulações, instrumentação, timbres, efeitos instrumentais e timing dos eventos musicais tem auxiliado na descrição estilistica de importantes compositores e instrumentistas brasileiros (ALMEIDA, 2005; FABRIS, 2005; FREITAS, 2005; ARAÚJO COSTA, 2006; FABRIS e BORÉM, 2006; MOREIRA JUNIOR, 2006; GOMES, 2007; LINHARES, 2007; NUNES, 2007; SILVA , 2007; SOARES, 2007; MAGALHÃES PINTO, 2009; BORÉM e GARCIA, 2010; CANÇADO, W. 2010; COSTA-LIMA NETO, 2010; VALENTE, 2011; LINHARES e BORÉM, 2011).

A sistematização de características do choro proposta por ALMEIDA (1999) e corroborada por SANTOS (2001) é um importante referencial tanto para a análise composicional quanto para a identificação de práticas de performance do gênero. Idealmente, o cenário ideal para esta identificação combina a percepção da música anotada e realizada, ou seja, as fontes primárias representadas por partituras e gravações. No caso de Pixinguinha, temos à disposição um rico acervo, constituído por partituras e leadsheets ${ }^{1}$ editadas ou manuscritas e por gravações representativas de suas performances, ou de colegas com os quais compartiIhava o que poderiamos chamar de estilo do choro.

Logo após a consolidação dos gêneros ragtime e blues nos Estados Unidos, na última década do século XIX, muitos grupos de músicos norte-americanos se beneficiaram de sua grande aceitação no meio musical europeu, ambos popular e erudito. Foram ágeis para logo absorver os traços marcantes do ragtime na sua música, compositores como Debussy (Goliwog's cake-walk do álbum Children's corner, 1908) e Stravinsky (Ragtime para onze instrumentos, 1918; o Ragtime de A História do soldado, 1918; Piano-Rag music, 1919) (KAMIEN, 1992, p.434; MACHLIS, 1990, p.476). A Paris do final do século XIX e início do século XX era considerada o centro cultural do mundo e atraía grandes artistas de toda parte. Bandas de jazz norte-americanas começaram a viajar para a Europa, levando o ragtime, já no ano de 1900 (SAGER, 2010) e, logo, se tornaram modelos para a música popular instrumental daquele continente. No final dos anos de 1920 já se observavam as primeiras bandas de jazz formadas por músicos franceses, pioneiros na Europa neste estilo. Em 1932, surgiu o Hot Club de France cujo Le Quintette atingiu reconhecimento internacional, especialmente com as brilhantes atuações de dois de seus membros: Django Reinhardt, no violão, e Stephane Grappelli, no violino (COSTA, 2011, p.82-88, neste volume de Per Musi).

Antes do início do processo de exportação de uma música tipicamente brasileira, a miscigenação, que sempre fez parte do longo processo de formação da cultura brasileira, acontecia dentro do país. A presença do lundu na música erudita, que remonta a 1819 na obra para piano 0 Amor brazileiro, foi possível com a vinda de um europeu - Sigismund Neukomm - para o Rio de Janeiro (APPLEBY, 1983, p.61; NEUKOMM, 2006). Entretanto, ao longo de todo o século XIX, uma música que pudesse ser reconhecida como genuinamente brasileira - surgida no meio popular e não no círculo erudito - permaneceu dentro de nossas fronteiras e não recebeu o patrocínio imperial, como a música marcadamente europeia de Carlos Gomes, Leopoldo Miguez, Henrique Oswald, Francisco Braga e Alberto Nepomuceno, para citar alguns (APPLEBY, 1983, p.28-93). Só em 1923, após a Semana de Arte Moderna, é que H. VillaLobos conseguiu se mobilizar para ir à França mostrar sua música, fato que ainda é considerado o principal marco da produção de uma música nacional fora do país. Entretanto, a ida de Pixinguinha com seu grupo a Paris é anterior coincide com o ano da Semana de Arte Moderna de 1922. Assim, podemos considerar Pixinguinha um dos primeiros casos, senão o primeiro, em que coincidem, no exterior, a exposição de uma música nacional e a absorção de elementos de uma música estrangeira.

Pixinguinha, em última análise, também atenderia à modernidade advogada por Mário de ANDRADE (1942, p.15) e seus colegas, sintetizadas em três princípios: (1) a atualização da inteligência artística brasileira (por exemplo, levando sua música a um centro artístico mundial, Paris), (2) a pesquisa estética (por exemplo, miscigenando estéticas diferentes, como a do choro e a do ragtime) e (3) a consolidação da criatividade brasileira (por exemplo, tornando-se o modelo do choro por excelência, apesar dos riscos de reinventá-lo). A universalidade de Pixinguinha, de que nos fala BASTOS (2005; veja mais detalhes à frente), é bem ilustrativa pelo fato de envolver três países: o Brasil (a música original), a França (o local) e os Estados Unidos (a influência). Esse processo de hibridação, que pode ser observado historicamente na música brasileira, se tornaria cada vez mais comum ao longo do século $X X$, envolvendo praticamente todos os principais movimentos da música popular, como a chanchada, a bossa-nova, a jovem guarda, o tropicalismo, o Clube da Esquina, o rock brasileiro etc. ${ }^{2}$

Da viagem de Pixinguinha com os Oito Batutas à França, Sérgio Cabral nos fala como o contato com músicos norteamericanos implicou em inúmeras mudanças na vida musical dos músicos brasileiros:

\footnotetext{
"os integrantes dos Oito Batutas falaram da convivência com os músicos de quatro jazz-bands, com os quais chegaram a tocar juntos" CABRAL (1997, p.80)

"Além de Pixinguinha na flauta e no sax, Palmieri no bandolim e China no vocal e no violão, os novos Oito Batutas passaram a contar com um pianista (J. Ribas), um pistonista (Bonfiglio de Oliveira...), um trombonista (Euclides Galdino), um baterista (Eugênio de Almeida Gomes, o Submarino) e mais um saxofonista (Luís Americano)" CABRAL (1997, p.35).
}

Rafael José de Menezes Bastos também fala deste contato de Pixinguinha com a música norte-americana em Paris em 1922, destacando que

"foi a partir dessa jornada que Pixinguinha começou a criar vínculos musicais e compatibilizar sua música com o jazz, que na época se encontrava em franco processo de se estabelecer como o novo universal da música popular" BASTOS (2005, p.179). 
Propõe-se, neste estudo de caso, explicar práticas de performance nos choros de Pixinguinha a partir dos acontecimentos históricos e de seus reflexos nas suas partituras e gravações. Para isso, o recorte das fontes primárias limitou-se à análise de duas obras: Um a zero, escolhida por ser emblemática das características do choro e por ter sido composta provavelmente em 1919 (apesar de ter sido gravada pela primeira vez apenas em 1946 e Segura ele, por ter sido composta em 1929 (após a viagem de 1922 de Pixinguinha à França) e conter mudanças estilísticas que refletem a influência do ragtime. Ambos os choros têm gravações históricas incluídas no CD Pixinguinha 100 anos (PIXINGUINHA, 1998), disco que tem a participação do próprio compositor como instrumentista: no choro Segura ele, Pixinguinha toca flauta e, em Um a zero, toca saxofone (ficando o solo de flauta nesta música por conta de Benedito Lacerda). Para este estudo, além das gravações de Pixinguinha, serão utilizadas como fontes primárias as leadsheets de Um a zero e Segura ele editadas por CARRASQUEIRA (1997).

Há controvérsias sobre a data de composição de Uma Zero. Alexandre Zamith Almeida relata o ano de 1949 e atribui uma co-autoria a Benedito Lacerda (ALMEIDA,1999, p.151). Carlos Sion e Tarik de Souza, no texto do encarte do CD Pixinguinha 100 anos, afirmam que sua gravação é anterior, de 1946 (SION e SOUZA, 1997), o que contradiz a informação de Almeida. Por outro lado, perspectiva que adotamos, Sérgio Cabral defende que a obra remonta a 1919, período em que Pixinguinha e Lacerda ainda não trabalhavam juntos, e que sua composição teria sido inspirada na conquista do Campeonato Sul-Americano pela seleção brasileira de futebol, na qual venceu a seleção uruguaia por um a zero (CABRAL, 1997, p.49).

Esses dois choros foram escolhidos para ilustrar o contraste estilistico em Pixinguinha, como compositor e como intérprete. Em Um a zero, tomado aqui como representante de um "grupo de controle", pode-se observar claramente a presença dos elementos tradicionais do choro (ALMEIDA, 1999; SANTOS, 2001). Já em Segura ele, embora algumas características do choro permaneçam, verificam-se traços de uma forte influência do ragtime norte-americano, cujas características são descritas por Tânia Mara CANÇADO (1999) e pelo próprio compositor e pianista norteamericano do início do século $X X$, Scott Joplin, considerado o maior expoente do gênero (CHASE, 1957).

\section{2 - Vestígios iconográficos da mudança estéti- ca na música de Pixinguinha e dos Oito Batutas} A documentação iconográfica da produção de Pixinguinha revela sua relação com o gosto do público e suas mudanças em função de sua "modernização" após a viagem a Paris no início de 1922. Quatro anos antes, no Rio de Janeiro de 1919, Pixinguinha liderou a criação de os Oito Batutas, cuja formação inicial tinha ele próprio na flauta e Donga (violão), China (canto, violão e canto), Nélson Alves (cavaquinho), Raul Palmieri (violão), Jacob Palmieri (bandola, pandeiro e reco-reco), José ("Zezé") Alves de
Lima (bandolim e ganzá) e Luís de Oliveira (bandola e reco-reco) (CABRAL, 1997, p.45; MARCONDES, ed., 1998, p.583), para tocarem na sala de espera do cinema Palais, no Rio de Janeiro. ${ }^{3}$ Essa formação de os Oito Batutas, é bem próxima da instrumentação dos chamados regionais ${ }^{4}$ que predomina até hoje nos grupos de choro, se ocupava de apresentar um repertório, nos primeiros anos de existência do grupo, exclusivamente de músicas brasileiras, como mostra um programa apresentado em 7 de julho de 1921 (CABRAL, 1997, p.68):

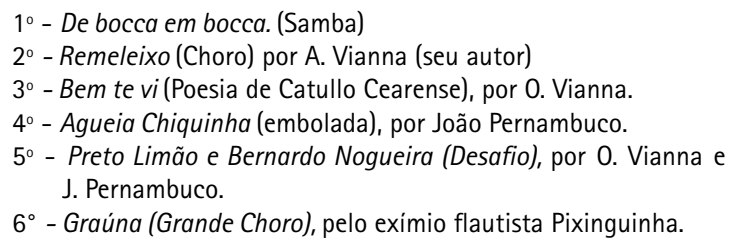

A crescente popularidade do grupo permitiu que Pixinguinha juntamente com os Oito Batutas viajasse pelo Brasil - São Paulo e Minas Gerais em 1919, Bahia e Pernambuco em 1921 - e se preparasse para vôos mais altos - Paris em 1922 e Argentina em 1923. Curioso e ávido, Pixinguinha procurava a cor da música local em cada região que tocava. Pelo Brasil, notou as diferenças regionais. No programa de concerto acima, percebe-se a inclusão de dois gêneros nordestinos - a embolada e o desafio, além de uma composição original sua com versos do poeta, teatrólogo, cantor e compositor maranhense Catulo da Paixão Cearense (1866-1946) (MARCONDES, ed., 1998, p.190).

A estadia de os Oito Batutas em Paris, financiados pelo milionário Arnaldo Guinle (MARCONDES, ed., 1998, p.583), foi longa. Durou aproximadamente seis meses e ocasionou mudanças profundas na estética do grupo, especialmente a partir da convivência com músicos norteamericanos na cena musical eclética da capital cultural (BASTOS, 2005). Pixinguinha trouxe, de Paris, um saxofone para si (MARCONDES, ed., 1998, p.634). Notadamente, estas mudanças ocorreram na instrumentação, na inclusão de novos gêneros e na forma de arranjar:

As influências do jazz, sofridas no exterior, tornaram-se evidentes, pela inclusão de saxofones, clarinetas e trompetes, pela utilização de arranjos instrumentais no estilo das jazz bands e pelas alterações no repertório, que passou a incluir fox-trots, shimmys, ragtimes e outros ritmos estrangeiros da moda (MARCONDES, ed., 1998, p.584).

A nova instrumentação do grupo mudou substancialmente sua sonoridade. Em muitas músicas houve a substituição de instrumentos tipicamente brasileiros - como o cavaquinho e o pandeiro - por outros, populares nos estados Unidos - como o banjo e a bateria. Um programa de concerto de 1923 com a relação das músicas de um show realizado na cidade de Santos (CABRAL, 1997, p.68), já após o retorno de os Oito Batutas da França, explicita 0 caminho híbrido escolhido:

10 Marcha "Meu passarinho" (Jazz Band Os Batutas)

$2^{\circ}$ Fox trot "Positively Absolutely" (Delsol and Nata)

3. Fox-blue "224" Effeito de Pistão (Jazz Band Os Batutas) 


\author{
$4^{\circ}$ Dança Americana (Miss. Nata) \\ $5^{\circ}$ Electrico - Solo de saxophone (Euclides) \\ 6 "Tango Argentino "Roxo" (Trio dos Batutas) \\ 7० Dança excêntrica "Lucky Day" (Mr. Delsol) \\ $8^{\circ}$ Courdy Fox (Jazz Band Os Batutas) \\ $9 \circ$ One step (Delsol and Nata) \\ $10^{\circ}$ Samba "Não posso comer sem molho" (Jazz Band \\ Os Batutas) \\ 11 Fantasia do "Charleston" (James Black)
}

Observa-se aí a inclusão de gêneros relacionados às bandas de ragtime norte-americanas, como a marcha militar, o fox trot, o blues e, ainda que com denominações pouco claras, alusões a uma "dança americana", a uma "dança excêntrica", a um "one step", e ao "Charleston". Em meio ao maciço abandono da música nacional que se observa neste programa, há lugar até para um "tango argentino". A internacionalização de os Oito Batutas é também visivel na própria maneira de se dirigir ao público, em que pode ser inferida certa valorização da cultura estrangeira, em detrimento da nossa, na excessiva utilização da língua inglesa: o programa denomina o grupo de "Jazz Band"; a preposição que une os co-autores do Fox trot "Positively Absolutely" é um "and" e não um "e"; há um espaço privilegiado para solos de trompete e saxofone. Em meio às onze peças apresentadas, há apenas um gênero brasileiro: o samba "Não posso comer sem molho", mas que, mesmo assim, é tocado por uma "Jazz Band".

\section{3 - Aspectos do choro tradicional em Um a zero} Se as origens do choro remontam ao final do século XIX e tem referências fundamentais na obras de Chiquinha Gonzaga, Joaquim Calado e Ernesto Nazareth (VERZONI, 2000) com outras designações como maxixe, tango brasileiro e polca, foi somente a partir da década de 1910 que o termo choro se consolidou (CAZES, 1998). Como acontece em muitos dos gêneros musicais populares, os mais conhecidos compositores de choro tendem a ser seus meIhores intérpretes FERRER (1996). Pixinguinha surgiu com as primeiras gerações dos chamados chorões e ainda é considerado seu maior expoente.

Um a zero, seja na sua partitura ou na gravação incluída no CD Pixinguinha 100 anos, é tomado aqui como modelo do choro por diversas razões. Ele confirma a formação instrumental do regional tradicional das rodas de choro: solistas (flauta e saxofone realizando contrapontos) e acompanhantes (violão, cavaquinho e pandeiro). Os solistas são esporadicamente substituídos por outros instrumentos melódicos, como a clarineta e o bandolim, entre outros. A informalidade na convivência e na realização musical, verificada no ambiente das rodas de choro por LARA FILHO, SILVA e FREIRE (2011, p.148-161, nesse volume de Per Musi), parece se refletir na realização rítmica mais relaxada do gênero, que se traduz em síncopas, como veremos em alguns exemplos, tanto nas linhas melódicas, quanto nas linhas de acompanhamento.

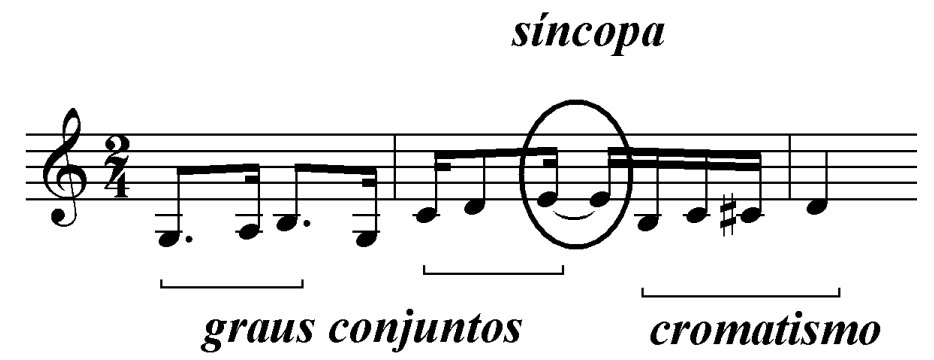

Ex.1 - Baixo condutor harmônico realizado pelo violão 7 cordas na gravação de Um a zero (CD Pixinguinha 100 anos).

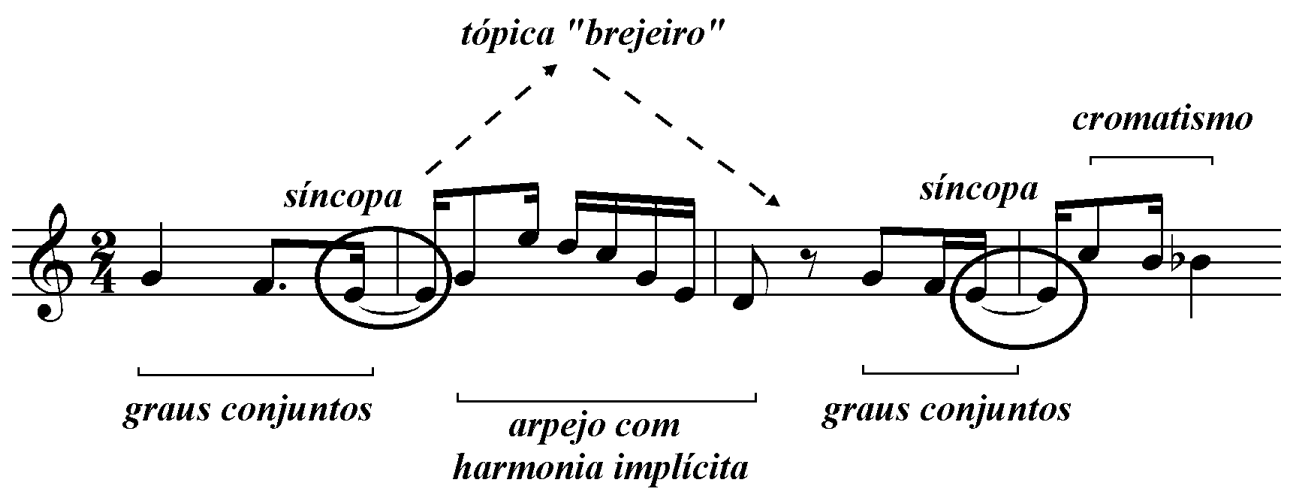

Ex.2 - Contracanto de Pixinguinha na gravação de Um a Zero (CD Pixinguinha 100 anos). 


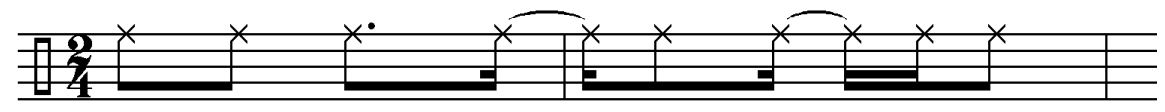

Ex.3 - Acompanhamento sincopado do cavaquinho em Um a zero (CD Pixinguinha 100 anos)
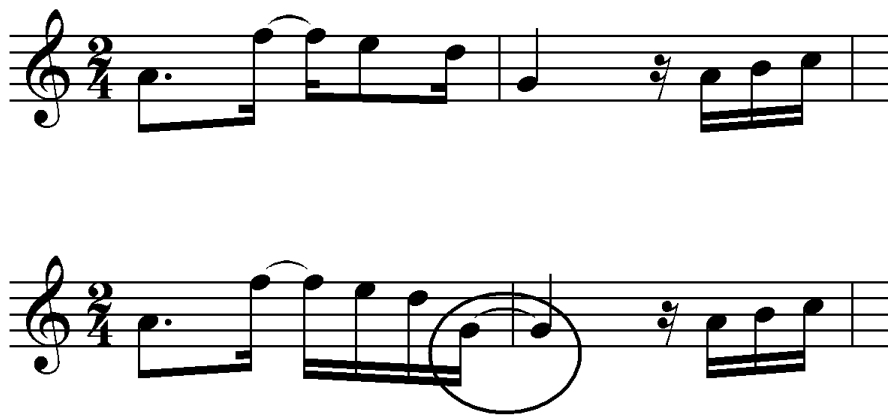

Ex.4 - Ritmo em trecho de Um a zero (c.5-6 da Seção A) na partitura e na sua realização antecipada por Benedito Lacerda (CD Pixinguinha 100 anos).

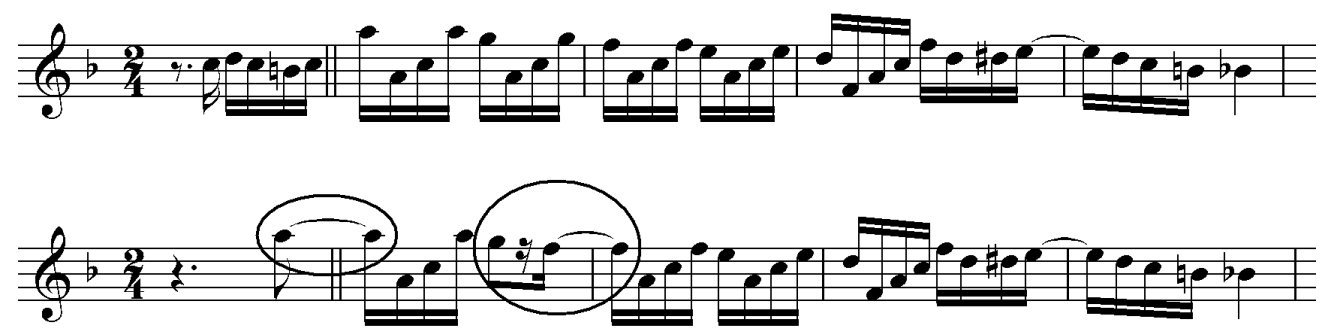

Ex.5 - Simplificação melódica e antecipações em trecho de Um a zero (c.49-51 da Seção C) na partitura e na sua realização por Benedito Lacerda (CD Pixinguinha 100 anos).

Na gravação, observa-se claramente o "baixo condutor harmônico", descrito por ALMEIDA (1999) e SANTOS (2001), no início da repetição da Seção A (Ex.1), baixo cujos graus conjuntos e ritmo sincopado o aproximam da natureza melódica dos solos.

Estudando traços típicos da música popular brasileira, Acácio PIEDADE (2011, p.103-112, nesse volume de Per Musi) destaca a tópica "brejeiro", ${ }^{5}$ muito encontrada no choro e caracterizada por ". . . subversões, brincadeiras, desafios, exibindo e exigindo audácia e virtuosismo, mas tudo isto de forma organizada, elegante, altiva, por vezes sedutora, maliciosa." Encontramos esse elemento nos contracantos improvisados ao saxofone por Pixinguinha, que além da função ornamental melódica, ainda cumprem a função de condução harmônica para o solo de flauta de Benedito Lacerda, como pode ser observado nos c.1-4 de Um a zero (Ex.2). Nesses contracantos podemos também observar ainda as antecipações típicas da flexibilidade rítmica do choro, o graus conjuntos e cromatismos observados também na linha do baixo.
No acompanhamento harmônico, pode-se observar a presença do timbre penetrante do cavaquinho que realiza um padrão sincopado característico (Ex.3).

Quanto à interpretação do solista Benedito Lacerda, podemos observar a liberdade rítmica com que toca a melodia, sem a preocupação de alinhamento vertical com o acompanhamento. Algumas notas são antecipadas, ilustrando o caráter que SANTOS (2001, p.5) descreve como uma "realização do ritmo de forma relaxada em relação ao pulso". 0 Ex.4 mostra primeiro, os c.5-6 da Seção A de Um a zero como normalmente aparecem nas partituras da música e, depois, a transcrição da realização do mesmo trecho na interpretação de Benedito Lacerda.

0 Ex.5 também mostra, nos c.49-51, além de mais duas ocorrências desse tipo de antecipações, duas simplificações rítmicas na realização de Benedito Lacerda, da Seção $C$ de Um a zero, o que é também outra característica na performance do choro. 


\section{4 - Aspectos do ragtime em Segura ele}

0 ragtime surge no fim do século XIX nos Estados Unidos, como um desdobramento e fusão das plantation songs com os cakewalks. A veiculação e refinamento dessa expressão artística afro-norte-americana acontecia principalmente no ambiente musical dos minstrel shows :

\begin{abstract}
"Os cantos acompanhados ao banjo dos músicos negros das plantations haviam sido a principal fonte da música que os músicos brancos criaram para a minstrelsyantes da Guerra Civil. .. Nas décadas subsequentes à guerra, o estilo dos músicos de banjo e o ritmo empertigado do cakewalk fundiram-se num novo tipo de música para piano que se chamou ragtime". (SABLOSKY, 1994, p.91)
\end{abstract}

No livro Do salmo ao jazz, CHASE (1957, p.397) destaca a proximidade entre os gêneros, argumentando que "... uma pequena lacuna separa as mais genuinas canções minstrel do século dezenove do autêntico estilo ragtime que emergiu poucas décadas depois", lacuna que do ponto de vista instrumental foi preenchida pelo piano, que se tornou característico ao estilo na sua migração das fazendas para os bares e salões das cidades. A disseminação do ragtime nas cidades levou ao surgimento de uma variedade de intérpretes do gênero:

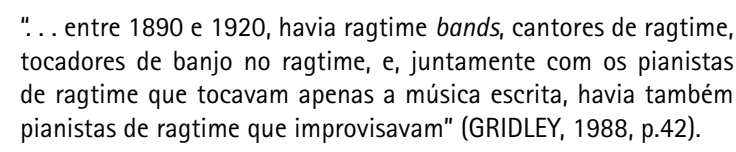
tocadores de banjo no ragtime, e, juntamente com os pianistas de ragtime que tocavam apenas a música escrita, havia também pianistas de ragtime que improvisavam" (GRIDLEY, 1988, p.42).

0 afro-americano Scott Joplin (1868-1917) tornou-se o mais popular compositor e pianista americano do gênero, "conhecido no final do século XIX como o Rei do Ragtime" (GROVE, 1994, p.479). No seu estilo de maturidade, Joplin chegou a uma fusão entre a herança escrava e a escrita da música europeia de salão.

Mas o caminho do ragtime até a música brasileira não foi o mais curto, mas sim via Europa. BASTOS (2005, p.180) fala da presença de cakewalk, seu precursor, na França:
"Desde o final do século XIX e início do XX, a França já vinha sendo "invadida" pelas danses exotiques e danses nouvelles (Apprill e Dorier-Apprill, 2001, p.31). As primeiras incluiam tudo que fosse estrangeiro; as segundas, especialmente as manifestações artísticas provindas das Américas - o cake walk norteamericano, o tango argentino, o maxixe brasileiro, o paso doble espanhol, a rumba cubana, entre outros".

Na gravação de Segura ele, podemos reconhecer muitos elementos do choro tradicional, como aqueles observados em Um a zero. Um dos elementos comuns entre o choro e o ragtime é sua estrutura formal a qual, assim como em diversos outros gêneros populares, é baseada no rondó ABA$\mathrm{CA}$. Mas traz também, e integrados à sua textura, elementos estranhos à roda tradicional de chorões e que podem ter significado uma grande mudança estilística na época.

Em depoimento a VALENTE (2011)?? sobre as diferenças na improvisação no choro e no jazz e suas relações com as mãos esquerda e direita no piano, Nailor "Proveta" de Azevedo fala da natureza da linha do baixo em ambos os gêneros: melódica e ritmicamente mais criativa no brasileiro, e mais contrita e subserviente à linha dos solistas no caso norte-americano. No ragtime, isto é bastante perceptível na rítmica de origem militar do acompanhamento simples, caracteristica que CANÇADO (1999, p.172-174) descreve como um "constante ritmo de marcha na linha do baixo", marcha que pode ser ouvida na gravação de Segura ele no CD Pixinguinha 100 anos (Ex.6). Outro elemento caracteristico do ragtime, e estranho ao choro tradicional, perceptível na audição desta faixa é a presença do banjo na instrumentação.

Outra característica na gravação de Segura ele, que pode ser relacionada ao ragtime, é o padrão rítmico cubano chamado cinquillo, observado no banjo e que, por meio de uma síncope sobre o segundo tempo, resulta em cinco notas por compasso (dai a origem do nome em espanhol, como mostra o Ex.7). Segundo CANÇADO (1999, p.152), esse padrão rítmico seria uma variação das "oito semicolcheias com uma ligadura entre os tempos", comum no ragtime.

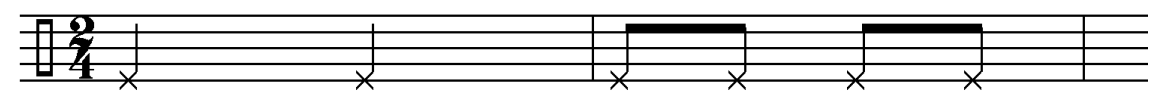

Ex.6 - Padrão rítmico da marcha militar do ragtime observado na linha do baixo (instrumento não identificado) de Segura ele no CD Pixinguinha 100 anos.

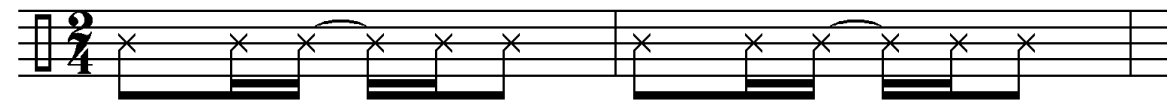

Ex.7 - Padrão rítmico do cinquillo cubano realizado pelo banjo em Segura ele no CD Pixinguinha 100 anos. 
Finalmente, recorremos à fala do maior compositor de ragtimes, Scott Joplin, para reconhecer outra possivel influência deste gênero na interpretação de Segura ele por Pixinguinha. Em um método no qual pretendia ensinar como tocar sua música, Joplin (citado por CHASE, 1957, p.408-409) diz que, para se obter os efeitos musicais que desejava, era necessário dar ". . . a cada nota a sua duração exata e observando escrupulosamente as ligaduras" e também que ". . . os exercícios estão harmonizados na suposição de que cada nota será tocada conforme está escrita, visto que o sentido que se quer dar à música depende disso e também da duração exata que se dá às notas." De fato, na gravação de Pixinguinha de Segura ele há um grande cuidado em alinhar verticalmente a melodia com a linha do baixo, evitando-se as assincronias decorrentes da liberdade rítmica do choro tradicional (especialmente antecipações e atrasos), como aquelas observadas na gravação de Um a zero, na performance do próprio Pixinguinha.

Tematicamente, podemos estabelecer uma conexão entre o choro Segura ele e um dos mais famosos ragtimes de todos os tempos, o The Entertainer de Scott Joplin. Trata-se de um motivo formado por uma apojatura seguida de síncopa. Este motivo ocorre nas seções $C$ de ambas as músicas (Ex.8). Em Segura ele, este motivo (com as mesmas notas!) é utilizado primeiro na cabeça do tempo e sem a síncopa e, depois, deslocado como anacruse. Esse deslocamento é um desafio rítmico para ouvidos não acostumados ao repertório, pois dá a sensação de uma métrica ternária (um 3/8) na rítmica tradicionalmente binária do choro, o que pode explicar o título escolhido por Pixinguinha.

\section{5 - Considerações finais}

A postura aberta de Pixinguinha em relação ao contato com outras culturas permitiu que ele absorvesse e incorporasse elementos que contribuíram na formação de seu estilo musical maduro e eclético. Suas demandas por uma música mais universal passam, primeiro, por uma ampliação de seus horizontes dentro do próprio país e, depois, fora dele. Sua estadia em Paris, em 1922, juntamente com seu grupo Oito Batutas, significou uma rica via de mão dupla, em que ele levou, pioneiramente, uma cultura musical genuinamente brasileira e consolidada à Europa e trouxe, na bagagem, instrumentos, formas de tocar e de se relacionar com o público que ampliaram a estética e vocabulário do choro.

Na gravação de Um a zero, composta antes da viagem de Pixinguinha à França, vimos que ele e Benedito Lacerda optaram por uma interpretação mais atenta às características tradicionais do choro. A instrumentação privilegia o cavaquinho, o violão, a flauta, e o pandeiro (apesar da sonoridade presente do saxofone, já incorporado no choro à época da gravação, mas não na época da composição). Do ponto de vista da realização rítmica, percebe-se o ritmo sincopado (mesmo nas linhas de acompanhamento) e a liberdade rítmica do solista em relação ao pulso.

Por outro lado, na gravação de Segura ele, composta após a viagem de Pixinguinha à França, vimos que ele rompe com cânones do choro tradicional ao buscar inspiração nos ragtimes das jazz bands e nos elementos formativos deste gênero norte-americano com os quais teve contato. Na instru-
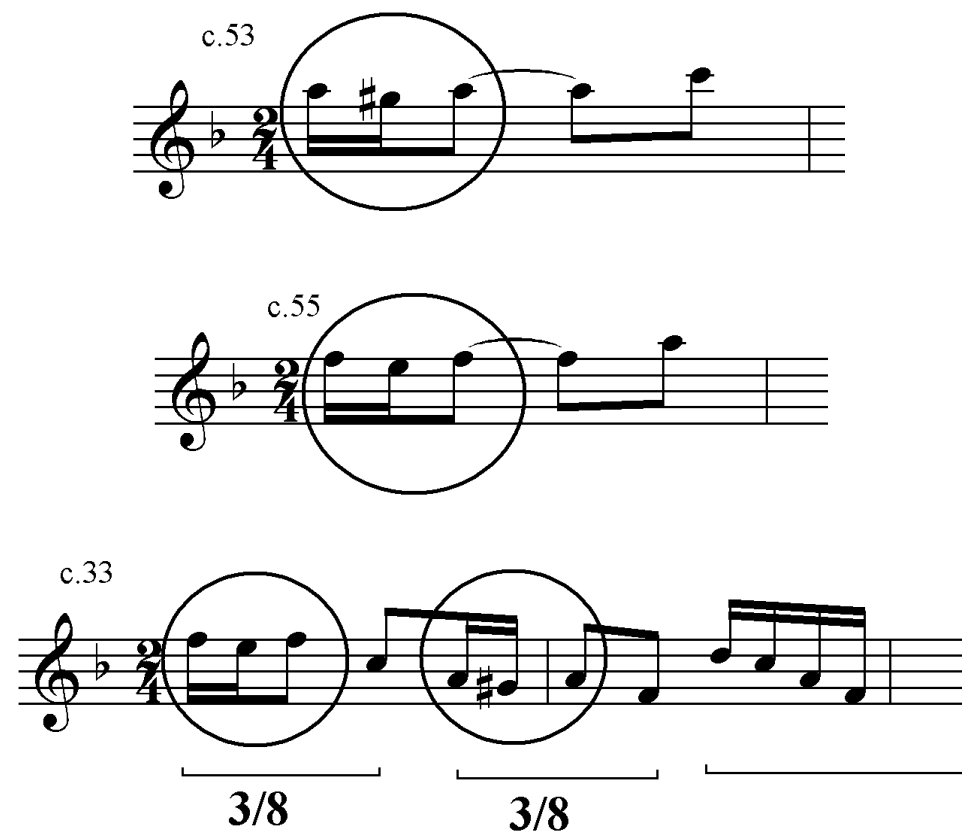

Ex.8 - Motivo comum entre a Seção C (c.53 e c.55) do ragtime The Entertainer de Scott Joplin e a Seção C (c.33-34) do choro Segura ele de Pixinguinha. 
mentação, inclui a sonoridade exótica do banjo. Na linha do baixo, recorre aos ritmos militares simples e sem síncopas. Ainda no acompanhamento, incorpora o ritmo do cinquillo nas levadas de preenchimento harmônico. Nesse ambiente, o molejo e flexibilidade brasileiros dão lugar a uma verticalidade sincrônica à qual o solista, ele, procura se ater.

Atestam também esta mudança estética em Pixinguinha e na história do choro brasileiro, por conseguinte, as novidades e modismos que se observam na comunicação entre os chorões e seu público, como a inclusão de gêneros musicais estrangeiros nos concertos, a adoção de termos na língua inglesa nos títulos das composições e suas descrições nos programas impressos.

Se houve uma falta de apoio governamental à primeira música de fato brasileira a ser ouvida na Europa e uma relativa subestima nos círculos eruditos, Radamés Gnattali, possivelmente o compositor que melhor sintetizou e compreendeu a integração entre as músicas erudita e a popular no Brasil, buscou reparar essa negligência histórica, homenageando-o como personagem central em um dos movimentos de sua Suite retratos (LIMA, 2011,p.113-123, nesse volume de Per Musi).

\section{Referências}

ALBINO, César; LIMA, Sonia R. Albano de. 0 percurso histórico da improvisação no ragtime e no choro. Per Musi, v.23. Belo Horizonte: UFMG, 2011, p.71-81.

ALMEIDA, Alexandre Zamith. Verde e amarelo em preto e branco: as impressões do choro no piano brasileiro. Campinas: Instituto de Artes, Universidade de Campinas, 1999. Dissertação (Mestrado em Música).

ALMEIDA, Hermínio Carlos de. Viver de Amor de Toninho Horta e Ronaldo Bastos: aspectos composicionais e de performance em um arranjo para trio de oboé, trompa e piano. Belo Horizonte: UFMG, 2006. (Dissertação de Mestrado)

ANDRADE, Mário de. O movimento modernista. Rio de Janeiro: casa do Estudante, 1942.

APPLEBY, David. P. The music of Brazil. Austin: Texas University Press, 1983.

ARAÚJO COSTA, Fabiano. Análise e realização de 4 leadsheets do Calendário do Som de Hermeto Pascoal segundo os conceitos harmônicos de Schoenberg. Belo Horizonte: UFMG, 2006. (Dissertação de Mestrado)

BASTOS, Rafael José de Menezes. Les Batutas, 1922: uma antropologia da noite parisiense. Revista Brasileira de Ciências Sociais. São Paulo, 2005, v.20, n.5, p.177-196.

BORÉM, Fausto; GARCIA, Maurício Freire. Cannon de Hermeto Pascoal: aspectos musicais e religiosos em uma obraprima para flauta. Per Musi, v.22. Belo Horizonte: UFMG, 2010. p.63-79.

CABRAL, Sérgio. Pixinguinha, vida e obra. Rio de Janeiro: Editora Lumiar, 1997.

CANÇADO, Tânia Mara Lopes. An Investigation of West African and Haitian Rhythms on the Development of Syncopation in Cuban Habanera, Brazilian Tango/Choro. Shenandoah Conservatory, Virginia, USA, 1999. (Tese de Doutorado em Música).

CANÇADO, Wilson Lopes. Novena, Crença e Gira Girou de Milton Nascimento e Márcio Borges: análise de suas três primeiras composições criadas em uma noite de 1964. Belo Horizonte: UFMG, 2010. (Dissertação de Mestrado)

CARRASQUEIRA, Maria José. O melhor de Pixinguinha. São Paulo: Editora Irmãos Vitale, 1997.

CAZES, Henrique. Choro, do quintal ao Municipal. São Paulo: Editora 34, 1998.

CHASE, Gilbert. Do salmo ao jazz: a música dos Estados Unidos. Trad. Samuel Reis e Lino Vallandro. Rio de Janeiro: Editora Globo, 1957.

COSTA, Adriana. Tiger Rag na interpretação do Le Quintette du Hot Club de France: história, análise e práticas de performance. Per Musi, v.23. Belo Horizonte: UFMG, 2011, p.82-88.

COSTA, Pablo Garcia da; CASTRO, Beatriz Magalhães. Elementos extra-musicais na obra de K-ximbinho: questões sobre iconografia musical em suas capas de disco entre 1950 e 1960. Per Musi, v.23. Belo Horizonte: UFMG, 2011, p.124-137.

COSTA-LIMA NETO, Luiz. 0 cantor Hermeto Pascoal: os instrumentos da voz. Per Musi, v.22. Belo Horizonte: UFMG, 2010. p.44-62.

FABRIS, Bernardo Vescovi. Catita de K-Ximbinho e a interpretação do saxofonista Zé Bodega: aspectos hibridos entre o choro e o jazz. Belo Horizonte: UFMG, 2005. Dissertação (Mestrado em Música).

FABRIS, Bernardo Vescovi; BORÉM, Fausto. Catita na leadsheet de K-Ximbinho e na interpretação de Zé Bodega: aspectos da hibridação entre o choro e o jazz. Per Musi, v.13. Belo Horizonte: UFMG, 2006. p.5-28. 
FERRER, Marcus. Uma música dinâmica e aberta. Revista Roda de Choro. Rio de Janeiro, 1996, v. 3, p.12-15.

FREITAS, Marcos Flávio de Aguiar. O choro em Belo Horizonte: aspectos históricos, compositores e obras. Belo Horizonte: UFMG, 2005. (Dissertação de Mestrado)

GOMES, Wagno Macedo. Chorando baixinho de Abel Ferreira: aspectos interpretativos do clarinetista compositor e do clarinetista Paulo Sérgio Santos. Belo Horizonte: UFMG, 2007. (Dissertação de Mestrado)

GRIDLEY, Mark C. Jazz Styles: History and Analysis. 3a Edição. New Jersey/ USA: Editora Prentice-Hall, 1988.

KAMIEN, Roger. Music: an appreciation. 5a. ed. New York: McGraw-Hill, 1992.

LARA FILHO, Ivaldo Gadelha de; SILVA, Gabriela Tunes da; FREIRE, Ricardo Dourado. Análise do contexto da Roda de Choro com base no conceito de ordem musical de John Blacking. Per Musi, v.23. Belo Horizonte: UFMG, 2011, p.148-161.

LIMA, Luciano Chagas. Ernesto Nazareth e a valsa da Suite Retratos de Radamés Gnattali. Per Musi, v.23. Belo Horizonte: UFMG, 2011, p.113-123.

LINHARES, Leonardo Barreto; BORÉM, Fausto. A composição e interpretação de Victor Assis Brasil em Pro Zeca: hibridismo entre o baião e o bebop. Per Musi, v.23. Belo Horizonte: UFMG, 2011, p.28-38.

LINHARES, Leonardo Barreto. Pro zeca de Victor Assis Brasil: aspectos do hibridismo na música instrumental brasileira. Belo Horizonte: UFMG, 2007. (Dissertação de Mestrado)

MACHLIS, Joseph; FORNEY, Kristine. The Enjoyment of music. 6a. ed. New York: W. W. Norton, 1990.

MAGALHÃES PINTO, Marcelo Gama e Mello de. Frevo para piano de Egberto Gismonti: uma análise de procedimentos populares e eruditos na composição e performance. Belo Horizonte: UFMG, 2009. (Dissertação de Mestrado)

MARCONDES, Marcos (Ed.). Enciclopédia da música brasileira: popular, erudita, e folclórica. 2a ed. Org. São Paulo: Art Editora, 1998.

MARIZ, Vasco. Heitor Villa-Lobos. 11 ed. Coleção Reconquista do Brasil. Belo Horizonte: Itatiaia, 1989.

MAURITY, Fernando Trocado. Improvisação em Victor Assis Brasil. Dissertação de mestrado. Rio de Janeiro: Universidade Federal do Estado do Rio de Janeiro, 2006.

MOREIRA JUNIOR, Nilton Antonio. Características do choro em Um a zero e do ragtime em Segura ele em duas gravações de Pixinguinha. Belo Horizonte: UFMG, 2006. (Dissertação de Mestrado)

NEUKOMM, Sigismund. O amor brazileiro, para piano. Ed. Fausto Borém. Belo Horizonte: Musa Brazilis, 2006. (Partitura)

NUNES, Alvimar Liberato. Raphael Rabello e Odeon de Ernesto Nazareth: interpretação, arranjo e improvisação. Belo Horizonte: UFMG, 2007. (Dissertação de Mestrado)

PIEDADE, Acácio. Expressão e sentido na música brasileira: retórica e análise musical. Revista Eletrônica de Musicologia, v.XI, 2007.

Jazz, música brasileira e fricção de musicalidades. Opus. v.11. Dez, 1985. In: www.anppom.com.br/opus (Acesso em 28 de fevereiro de 2009).

Musica Instrumental Brasileira e Fricção de Musicalidades, In Rodrigo Torres (ed.) Música Popular em América Latina: Actas del Ilo. Congresso Latinoamericano del IASPM. Santiago de Chile: Fondart, 1999.

Perseguindo fios da meada: pensamentos sobre hibridismo, musicalidade e tópicas. Per Musi. N.23. Belo Horizonte: UFMG, 2011. p.103-112.

PINTO, Marco Túlio de Paula. Victor Assis Brasil: a importância do período na Berklee School of Music (1969-1974) em seu estilo composicional. Per Musi, v.23. Belo Horizonte: UFMG, 2011, p.45-57.

PIXINGUINHA. Pixinguinha 100 anos. Org. Carlos Sion e Tarik de Souza. São Paulo: Sony e BMG (CD 743214628621), 1998.

SABLOSKY, Irving. A musica norte-americana. Rio de Janeiro: J. Zahar, 1994.

SADIE, Stanley (Ed.). Dicionario Grove de música: edição concisa. Rio de Janeiro: Jorge Zahar, 1994.

SAGER, David. A History of ragtime. http://lcweb2.loc.gov/diglib/ihas/loc.natlib.ihas. 200035811. (Acesso em 03 de fevereiro, 2010.

SANTOS, Rafael dos. Análise e considerações sobre a execução dos choros Canhoto e Manhosamente de Radamés Gnattali, Per Musi. Belo Horizonte: UFMG,2001, v.3, p.5-16.

SILVA, Flávio Mateus da. Marcos Leite e o grupo vocal Garganta Profunda: aspectos históricos e estilísticos no arranjo vocal de 0 Pato. Belo Horizonte: UFMG, 2007. (Dissertação de Mestrado)

SION, Carlos e SOUZA, Tarik de. Pixinguinha 100 anos. Compact disc. BMG Brasil. São Paulo, 1997.

SOARES, Márcio Ronei Cravo. A canção Todo o Sentimento, de Chico Buarque e Cristóvão Bastos: um exercício de leitura verbo-musical. Belo Horizonte: UFMG, 2007. (Dissertação de Mestrado)

VALENTE, Paula Veneziano. Horizontalidade e verticalidade: os modelos de improvisação de Pixinguinha e K-Ximbinho no choro brasileiro. Per Musi, v.23. Belo Horizonte: UFMG, 2011, p.162-169.

VERZONI, Marcelo Oliveira. Os primórdios do "choro" no Rio de Janeiro. UNIRIO, Rio de Janeiro, 2000. Tese (Doutorado em Música). 


\section{Notas}

1 Lead sheet é uma partitura simplificada, geralmente de músicas populares, que "geralmente inclui apenas a melodia e os acordes simplificados na forma de cifras e, algumas vezes, detalhes rítmicos ("convenções") ou de instrumentação. (FABRIS, 2005).

2 Para algumas discussões sobre hibridação na música popular brasileira, veja PIEDADE (2011; neste volume de Per Musi) e ALBINO e LIMA (2011; neste volume de Per Musi); para estudos de caso sobre K-Ximbinho, veja FABRIS e BORÉM (2006); COSTA e CASTRO (2011; neste volume de Per Musi) e VALENTE (2011; neste volume de Per Musi); sobre Hermeto Pascoal, veja BORÉM e GARCIA (2010) e COSTA-LIMA NETO (2010); sobre Victor Assis Brasil, veja LINHARES e BORÉM (2011; neste volume de Per Musi); PINTO (2011; neste volume de Per Musi), MAURITY (2006); PIEDADE (1985) e PIEDADE (1999).

30 número de músicos no grupo dos Oito Batutas, mais tarde renomeado simplesmente como Batutas, variou ao longo de sua história, chegando a contar com 12 membros (MARCONDES, ed., 1998, p.584).

40 regional de choro é um grupo instrumental geralmente formado por instrumentos de acompanhamento, como o cavaquinho, violão de 7 cordas, violão de 6 cordas (opcional), pandeiro e outros instrumentos de percussão (opcionais), e instrumentos solistas, como a flauta, clarineta, bandolim, cavaquinho e acordeom.

5 Tópicas são figuras de retórica utilizadas como elemento característicos de expressão e de sentido na música. Veja mais em PIEDADE (2011, 2007).

6 Plantation songs são canções autênticas dos negros das fazendas do sul dos Estados Unidos no final do século XIX, normalmente apresentadas em espetáculos dos brancos e geralmente acompanhadas pelo banjo (GROVE, p.11).

7 Minstrel shows eram espetáculos de variedades, nos quais intérpretes de rostos pintados de preto parodiavam os negros, onde se cantavam as plantations songs e o cakewalk (GROVE, p.11).

8 Para outras semelhanças e diferenças entre o choro e o ragtime, veja ALBINO e LIMA (2011), às p.71-81 nesse volume de Per Musi.

Nilton Moreira é Doutorando em Música pela UNIRIO, Mestre em Música e Bacharel em Flauta Transversa pela UFMG. Atualmente é bolsista do CNPq, sendo orientado pelo professor Sérgio Barrenechea. Foi orientado no Mestrado pelos professores Maurício Freire e Fausto Borém na UFMG, onde foi bolsista da CAPES. Estudou com Artur Andrés, Toninho Guimarães, fez máster classes com os professores Michel Debost (França), Michael Heisel (Alemanha), Renato Axelrud, Odette Ernest, Andréa Ernest, Toninho Carrasqueira, entre outros. Atua junto à Orquestra Filarmônica do Espírito Santo como músico convidado. Já atuou como músico convidado junto à Orquestra Sinfônica Nacional e Orquestra Ouro Preto. Foi professor da Universidade Vale do Rio Verde, no curso de Licenciatura em Música em 2007 e 2008 e professor de Flauta Transversa na Faculdade de Música do Espírito Santo em 2009. Na área da MPB, integra o Sexteto Patápio Silva, com o qual tem um CD gravado. Ganhou os concursos Jovem Solista da UFMG (2003), Jovem Músico BDMG (2004) e "Orquestra para Todos" da Orquestra Sinfônica Brasileira (2005).

Fausto Borém é Professor Titular da Escola de Música da Universidade Federal de Minas Gerais (UFMG), onde criou o Mestrado em Música e a Revista Per Musi. É pesquisador do CNPq desde 1994 e seus resultados de pesquisa incluem um livro, três capítulos de livro, dezenas de artigos sobre práticas de performance e suas interfaces (composição, análise, musicologia, etnomusicologia e educação musical) em periódicos nacionais e internacionais, dezenas de edições de partituras e apresentação de recitais nos principais eventos nacionais e internacionais do contrabaixo. Recebeu diversos prêmios no Brasil e no exterior como solista, teórico, compositor e professor. Acompanhou músicos eruditos como Yo-Yo Ma, Midori, Menahen Pressler, Yoel Levi, Fábio Mechetti, Luiz Otávio Santos, Arnaldo Cohen, Antônio Menezes e músicos populares como Hermeto Pascoal, Egberto Gismonti, Henry Mancini, Bill Mays, Kristin Korb, Grupo UAKTI, Toninho Horta, Juarez Moreira, Tavinho Moura, Roberto Corrêa e Túlio Mourão. Participou do CD e DVD O Aleph de Fabiano Araújo Costa. 